\title{
A CROSS SECTIONAL STUDY: ASSESSMENT OF MATERNAL RISK FACTORS FOUND IN LOW BIRTH WEIGHT NEONATES
}

\section{Dr. Nikulkumar Thakkar* \\ Dr. Shalini Panday}

\section{Dr.Nomeeta Gupta}

\author{
Peadiatrician, Janta hospital, Jivan Jyoti charitable trust, Patan, Gujarat \\ ${ }^{*}$ Corresponding Author
}

Senior consultant, Department of pediatrics, Batra Hospital and Medical Research Centre Delhi. Centre

ABSTRACT Introduction Birth weight is one of the important factors for the survival, normal growth and development of a child. LBW is associated with compromised growth, disabilities, hospitalizations, brain damage, and poorer language development, increased risk of cardiovascular and metabolic disorders in adult life. Maternal risk factor that may contribute to LBW include age, stature, socioeconomic status, multiple pregnancies, previous LBW infants and poor nutrition. Method: The present cross-sectional study was carried out in the postnatal care wards and NICU of Janta trust hospital, Patan. All live born babies born at Janta Hopsital with birth weight of less than 2.5kg during July 2019 to June 2020 were included after written consent from parents. The information regarding the study variables was record on predesigned, pretested questionnaire. Result: Out of 65 LBW babies, $46.2 \%$ were boys. Percentage of LBW babies was similar in second para and above (52.3\%) as compared to primiparous mothers (47.7\%). Eighteen babies (18, 27.7\%) were born pre term. About 3.1\% LBW babies had very low birth weight. The proportion of LBW babies was higher in 20-24 year age group (52.3\%). Majority of mothers studied up to primary $(84.8 \%)$. Total $63.1 \%$ had an antenatal registration with in the first trimester. Half of mothers $(52.3 \%)$ visited adequately during antenatal period. Most common maternal factors found in LBW mothers were anemia (55.4\%), PIH (12.0\%) followed by UTI (7.7\%) fever (6.2\%) and APH (6.2\%). Conclusion: Maternal factors like teenage pregnancy, illiteracy of the mothers, lower socioeconomic status, short birth spacing, lack of antenatal care were observed higher among low birth weight newborn. There is the need to strengthen the maternal services at community level.

\section{KEYWORDS :}

\section{INTRODUCTION}

The major causes of the infant mortality rate are low birth weight (LBW) and premature babies, birth asphyxia and infections in developing country. Birth weight is one of the important factors for the survival, normal growth and development of a child. ${ }^{-1}$ LBW has been defined by the World Health Organization (WHO) as weight at birth of less than 2,500 grams irrespective of gestational age. ${ }^{2}$ There are multiple causes of LBW including early induction of labour or caesarean birth, multiple pregnancies, pre-eclampsia, eclampsia, infections and chronic conditions such as high blood pressure and diabetes.

LBW is associated with compromised growth, disabilities, hospitalizations, brain damage, and poorer language development, increased risk of cardiovascular and metabolic disorders in adult life., ${ }^{4,5}$ Maternal risk factor that may contribute to LBW include age, stature, socioeconomic status, multiple pregnancies, previous LBW infants, poor nutrition, infection like tuberculosis, anemia, hemorrhage, chronic heart disease or hypertension, diabetes, urinary tract infection, any past obstetric history, maternal (medical) illness, drug addiction, alcohol abuse, smoking. Proper care is to be given even before a woman conceives, during pregnancy, delivery and after the birth. ${ }^{6}$ These factors are depending upon geographic, socioeconomic and cultural factors. Thus it is necessary to identify factors prevailing in a particular are a responsible for low birth weight, so as to plan the strategy to tackle this important problem. This study was conducted to study the maternal factors associated with low birth weight at Janta trust hospital, Patan.

\section{METHODS}

The present cross-sectional study was carried out in the postnatal care wards and NICU of Janta trust hospital, Patan after approval from institutional ethic committee. All live born babies born at Janta Hopsital with birth weight of less than $2.5 \mathrm{~kg}$ during July 2019 to June 2020 were included after written consent from parents. Extramural newborn babies, still born and baby with congenital malformation were excluded. The information regarding the study variables was record on predesigned, pretested questionnaire. It included socio demographic details, antenatal history and natal history (labour and delivery history) of the mother, birth weight, length, and head circumference. Also their case files were reviewed for further additional information.

\section{STATISTICAL ANALYSIS:}

The data was entered into Microsoft excel 2010 and processed with EPI INFO Ver.7 software. Qualitative data was presented in frequency and percentage However quantitative data was presented in mean and standard deviation. The " $p$ " values less than 0.05 was considered as significant.

\section{RESULT}

Table 1 showed Characteristics of LBW babies. Out of 65 LBW babies, 30 (46.2\%) were boys and $35(53.8 \%)$ were girls. Percentage of LBW babies was similar in second para and above $(34,52.3 \%)$ as compared to primiparous mothers (31, $47.7 \%)$. Inter pregnancy interval less than 18 months was observed in 18 birth (47.1\%). Eighteen babies (18, 27.7\%) were born pre term. No any infant was born after 42 weeks. Six newborn (3.1\%) had very low birth weight (less than $1.5 \mathrm{~kg}$ ).

Table 1: Characteristics of LBW babies

\begin{tabular}{|c|c|c|}
\hline Gender & Frequency & Percentage (\%) \\
\hline Male & 30 & 46.2 \\
\hline Female & 35 & 53.8 \\
\hline Birth order & & \\
\hline $1^{\text {st }}$ & 20 & 30.8 \\
\hline $2^{\text {nd }}$ & 27 & 41.5 \\
\hline $3^{\text {rd }}$ & 15 & 23.1 \\
\hline $4^{\text {th }}$ & 2 & 3.1 \\
\hline $5^{\text {th }}$ & 1 & 1.5 \\
\hline *Birth gap (months) $\mathbf{n = 3 4}$ & & \\
\hline
\end{tabular}




\begin{tabular}{|c|c|c|}
\hline less than 18 & 16 & 47.1 \\
\hline 18 to 23 & 13 & 38.2 \\
\hline$\geq 24$ & 5 & 14.7 \\
\hline Gestational age (Weeks) & & \\
\hline$<28$ & 1 & 1.5 \\
\hline $28-32$ & 2 & 3.1 \\
\hline $33-36$ & 15 & 23.1 \\
\hline $37-42$ & 47 & 72.3 \\
\hline$>42$ & 0 & 0 \\
\hline Birth weight $(\mathrm{kg})$ & & \\
\hline$\leq 1$ & 0 & 0.0 \\
\hline 1.1 to 1.5 & 2 & 3.1 \\
\hline 1.6 to 2.0 & 13 & 20.0 \\
\hline 2.1 to 2.5 & 50 & 76.9 \\
\hline Total & 65 & 100 \\
\hline
\end{tabular}

Table 2: Characteristics of mother

\begin{tabular}{|c|c|c|}
\hline Locality & Frequency & Percentage (\%) \\
\hline Rural & 52 & 80.0 \\
\hline Urban & 13 & 20.0 \\
\hline \multicolumn{3}{|l|}{ Religion } \\
\hline Hindu & 61 & 93.8 \\
\hline Muslim & 4 & 6.2 \\
\hline other & 0 & 0 \\
\hline \multicolumn{3}{|l|}{ SE class } \\
\hline l (Upper) & 0 & 0 \\
\hline 2 (Upper Middle) & 0 & 0 \\
\hline 3 (Lower Middle) & 9 & 13.8 \\
\hline 4 (Upper Lower) & 35 & 53.8 \\
\hline 5 (Lower) & 21 & 32.3 \\
\hline \multicolumn{3}{|l|}{ Age of mother } \\
\hline $15-19$ & 9 & 13.8 \\
\hline $20-24$ & 34 & 52.3 \\
\hline $25-29$ & 12 & 18.5 \\
\hline$\geq 30$ & 10 & 15.4 \\
\hline \multicolumn{3}{|l|}{ Education of mother } \\
\hline Illiterate & 22 & 33.8 \\
\hline Primary & 33 & 50.8 \\
\hline Secondary & 5 & 7.7 \\
\hline Higher secondary & 3 & 4.6 \\
\hline Graduate & 2 & 3.1 \\
\hline \multicolumn{3}{|l|}{ Occupation of mother } \\
\hline Working women & 28 & 43.1 \\
\hline Housewife & 37 & 56.9 \\
\hline \multicolumn{3}{|l|}{ Antenatal registration } \\
\hline Within lst trimester & 41 & 63.1 \\
\hline $2^{\text {nd }}$ trimester & 12 & 18.5 \\
\hline $3^{\text {rd }}$ trimester & 12 & 18.5 \\
\hline \multicolumn{3}{|l|}{ Adequate ANC visit } \\
\hline Yes & 34 & 52.3 \\
\hline No & 31 & 47.7 \\
\hline Total & 65 & 100 \\
\hline
\end{tabular}

A majority of mothers $(52,80.0 \%)$ were from the rural areas. Total 61 (93.8\%) belonged to Hindu religion followed by Muslim (4,6.2\%). The proportion of LBW babies was higher in $20-24$ year age group (52.3\%). Majority of mothers studied up to primary $(55,84.8 \%)$. Based on Modified Kuppuswamy's socioeconomic scale, 21 (32.3\%) of total mothers were from the lower SE class. Total 41 women (63.1\%) had an antenatal registration with in the first trimester. Half of mothers (34, $52.3 \%$ ) visited adequately (min 4 visits) during antenatal period.

Table 3: Distribution of LBW babies according to maternal disease

\begin{tabular}{|c|c|c|}
\hline Maternal Disease & Frequency & Percentage (\%) \\
\hline Anemia & 36 & 55.4 \\
\hline Hypertension & 8 & 12.0 \\
\hline Pre eclampsia & 5 & 7.7 \\
\hline
\end{tabular}

\begin{tabular}{|c|c|c|}
\hline Eclampsia & 3 & 4.6 \\
\hline UTI & 5 & 7.7 \\
\hline Fever during pregnancy & 4 & 6.2 \\
\hline APH & 4 & 6.2 \\
\hline Gestational DM & 4 & 6.2 \\
\hline Previous abortion & 3 & 4.6 \\
\hline PROM >18 hrs & 3 & 4.6 \\
\hline Oligohydromniosis & 2 & 3.1 \\
\hline Polyhydromniosis & 2 & 3.1 \\
\hline Uterine anomaly & 1 & 1.5 \\
\hline Heart disease & 0 & 0.0 \\
\hline
\end{tabular}

Most common maternal factors found in LBW mothers were anemia $(55.4 \%)$, PIH (12.0\%) followed by UTI $(7.7 \%)$ fever (6.2\%) and $\mathrm{APH}(6.2 \%)$.

\section{DISCUSSION}

In the present study, half of the LBW newborns were (46.2\%) boys. Proportion of LBW babies was similar in second para and above (52.8\%) as compared with primiparous mothers (47.6\%). Christopher GL et al. observed similar proportion of LBW male. A study from Nagpur reported higher percentage of LBW (43.0\%) in primiparous mothers.

In the present study, the proportion of LBW was high $(47.1 \%)$ when interpregnancy interval was less than 18 months which is similar to the study conducted by Gawande et al (44.7\%).8 In the present study, more than one forth babies (27.7\%) were born pre term. Christopher GL et al. reported higher proportion of preterm birth (33.4\%).

Socio economic status of the household and education of mother strongly determines LBW status of the baby. In the present study, $52.3 \%$ mothers belonged to $20-24$ year age group and one third mothers were illiterate. Nearly one third mothers (31.3\%) were from the lower SE class. About 2/3rd women $(62.8 \%)$ had antenatal registration with in the first trimester and half of mothers $(52.3 \%)$ visited adequately during antenatal period.

A study conducted in Nagpur shows higher proportion of low birth weight in the teenage mothers $(41 \%)$, which decreases as the age increases.7 This may be because of complications of pregnancy increases as the age advances. Significant association between antenatal care and birth weight of baby was also reported in this study.8 Joshi HS reported $45 \%$ of LBW babies delivered by illiterate mothers.

\section{CONCLUSION}

Our results suggest that socio-economic status still determines birth weight it can be better addressed by universal antenatal care and institutional deliveries. A proportion of other factors like teenage pregnancy, illiteracy of the mothers, lower socioeconomic status, short birth spacing, lack of antenatal care were observed higher among low birth weight newborn. There is the need to strengthen the maternal services at community level.

\section{ACKNOWLEDGEMENT}

I express my sincere gratitude to Mr. Manskukh Patel, trustee of Jivan Jyoti charitable trust for constant support throughout the study. I want to thank to subjects without whom this study would not have been completed.

\section{DECLARATIONS}

Funding: None

Conflict of interest: None declared

Ethical approval: The study was approved by the Institutional Ethics Committee.

\section{REFERENCES}

1. Metgud CS, Naik VA, Mallapur MD. Factors affecting birth weight of a 
newborn-a community based study in rural Karnataka, India. PloS one. 2012 Jul 5;7(7):e40040.

2. Targets G. 2025, To improve maternal, infant and young child nutrition. World Health Organisation. Available: http://www. who. int/nutrition/global-target2025/en/. Accessed. 2020 Jul;27.

3. Larroque B, Bertrais S, Czernichow P, Léger J. School difficulties in 20-yearolds who were born small for gestational age at term in a regional cohort study. Pediatrics. 2001 Jul 1;108(1):111-5.

4. Walden RV, Taylor SC, Hansen NI, Poole WK, Stoll BJ, Abuelo D, Vohr BR. Major congenital anomalies place extremely low birth weight infants at higher risk for poor growth and developmental outcomes. Pediatrics. 2007 Dec 1;120(6):el512-9.

5. Valdez R, Athens MA, Thompson GH, Bradshaw BS, Stern MP. Birthweight and adult health outcomes in a biethnic population in the USA. Diabetologia. 1994 Jun 1;37(6):624-31.

6. Sachdev HP. Low birth weight in South Asia. Int J Diabetes DevCtries. 2001;21:13-33.

7. Christopher GL (2018) The Effect of Biological Factors on Birth Weight and Gestation in South Indian New-Borns. JPediatr Neurol Med 3: 130

8. Gawande UH, Pimpalgaonkar MS, Betharia SH. Biosocial determinants of birth weight in rural and urban Nagpur. Indian J Comm Med. 1994;25(2):64-7.

9. Joshi HS, Subba SH, Dabral SB, Dwivedi S, Kumar D, Singh S. Risk factors associated with low birth weight in newborns. Indian I Community Med. 2005 Oct 1;30(4):142-3. 